\title{
Editorial Introduction: behavioural climate policy
}

This special issue, guest edited by Sander van der Linden, Adam Pearson and Leaf Van Boven, is, as the title of the issue suggests, focused upon the most pressing issue of our time (indeed, perhaps of all time): climate change.

The issue begins with a detailed introduction by the guest editors, which is followed by seven standalone but interrelated articles. In the main, these articles do not focus upon particular climate change policies, but rather examine and explore people's beliefs, preferences and attitudes towards climate change (and some related policies), with particular consideration of the power of norms. These are clearly important considerations in attempting to discern which interventions might be effective in tackling the seismic challenge of climate change, and although the articles are US-centric, the arguments and evidence contained within them are of global significance.

We will not offer further spoilers as to the content of this special issue. Without further ado, we will hand proceedings over to the guest editors.

ADAM OLIVER 